$$
\text { "filep" — 2005/2/17 — 19:05 — page 337 — \#1 }
$$

\title{
A new approach for explaining Rhind's Recto - and its utility in teaching
}

\author{
LÁSZLÓ FILEP
}

Abstract. The Recto is a table in the Rhind Mathematical Papyrus (RMP) of ancient Egypt containing the unit fraction decompositions of fractions $2 / n(3 \leq n \leq 101, n$ odd $)$. To the question how (and why) the decompositions were made, there exists no generally accepted answer. The fact that in some other sources of Egyptian mathematics decompositions different from those in Recto exist makes the problem more difficult.

Researchers normally try to find the answer in some formulas by which the entries of the table were calculated [see e.g. 1, 42]. We are convinced that the correct answer is not hidden in formulas but in the characteristics of Egyptian mathematics namely those of fraction and division concepts. To study them is important not only from historical point of view but also from methodological one: how to develop fraction concept and how to make division easier.

Key words and phrases: egyptian mathematics, Rhind's Recto, unit fraction.

ZDM Subject Classification: F10.

\section{On Egyptian mathematics and RMP}

We summarise shortly the basic information and generally accepted views on the characteristics of ancient Egyptian arithmetic and especially on RMP. For further details, see [2], [6], [12] and [15]. Egyptian arithmetic was an additive one, i.e. they used only addition. Multiplication and division were led back to addition, namely to doubling and halving. The division $k / n$ was understood as: calculate with $n$ till you get $k$ ( $k, n$ are positive integers).

Copyright (C) 2004 by University of Debrecen 


$$
\text { "filep" — 2005/2/17 — 19:05 — page 338 — \#2 }
$$

The problems show practical origin and were solved by specific methods. There are no signs for any generalisation regarding either formulation or solution. This is one reason for dropping away formulas in our treatise. To support the claim that "practical" arithmetic was essentially different from ours and the Greeks' "theoretic" one, let's quote the words of Plato [Laws $819 \mathrm{~A}-\mathrm{C}$ ], and the scholiast of Plato's Charmides 165 E who uses "logistic" instead of practical arithmetic:

"Freeborn boys should learn so much of these things as vast multitudes of boys in Egypt learn along with their letters. First there should be calculations specially devised as suitable for boys, which they should learn with amusement and pleasure, for example, distributions of apples or garlands where the same number is divided among more or fewer boys, or (distributions) of the competitors in boxing or wrestling matches on the plan of drawing pairs with byes, or by taking them in consecutive order, or in any of the usual ways; and again there should be games with bowls containing gold, bronze, and silver (coins?) and the like mixed together, or the bowls may be distributed as undivided units; for, as I said, by connecting with games the essential operations of practical arithmetic,..." (see [8], Vol. 1, pp. 19-20)

"Logistic is the science which deals with numbered things, not numbers; it does not take number in its essence, but it presupposes 1 as unit, and the numbered object as number, e.g. it regards 3 as a triad, 10 as a decad, and applies the theorems of arithmetic to such (particular) cases. Thus it is logistic which investigates on the one hand what Archimedes called the cattle-problem, and on the other hand melites and phialites numbers, the latter relating to bowls, the former to flocks (he should probably have said "apples"); in other kinds too it investigates the numbers of sensible bodies, treating them as absolute. Its subject-matter is everything that is numbered. Its branches include the so-called Greek and Egyptian methods in multiplications and divisions, the additions and decompositions of fractions; ..." (see [8], Vol. 1, pp. 14-15)

The RMP, an important source of Egyptian mathematics, starts with the mysterious Recto. In the RMP and other sources all the fractions $k / n$ are represented as a sum of different unit fractions (i.e. fractions with numerator 1 ) and $2 / 3$. The special role of $2 / 3$ shows that the concept of numerator was not present in Egyptian arithmetic. The common concept of unit fraction and $2 / 3$ was "the part". In the following the phrase "unit fraction" will be used in Egyptian sense: fractions with numerator 1 , and $2 / 3$.

The RMP and other mathematical sources date back to the Middle Kingdom (2000-1800 B.C.). We do not have the original RMP, only a copy written by a 


$$
\text { "filep" — 2005/2/17 — 19:05 — page 339 — \#3 }
$$

scribe, Ahmes around 1650 B.C. Many researchers share the view that the papyrus - especially its Recto - was compiled by different scribes not living at the same time. Thus we have to differentiate also between inventor and applicator scribes. Ahmes probably belongs to the second category.

\section{The literal translation of Recto}

The best way to formulate of a new approach is to go back to the original source, in our case to the literal translation of the RMP by A. B. Chase [2]. As for the notations of "parts" we will follow [9]: $3^{\prime \prime}$ for $2 / 3, n^{\prime}$ for other unit fractions. Let's quote the literal translations of the plates 2,6 and 30 containing the decompositions of $2 / 3,2 / 5,2 / 7 ; 2 / 19$ and $2 / 89,2 / 91$ respectively.

\section{$\underline{\text { Plate } 2}$}

2 divided by 3

Call 2 out of $3^{1}$

$$
3^{\prime \prime} 2
$$

2 divided by 5

$$
5
$$$$
\begin{array}{lllll}
3^{\prime} & 1 & 3^{\prime \prime} & \mathbf{1 5}^{\prime} & 3^{\prime}
\end{array}
$$

Working out:

$$
\begin{array}{ccc}
1 & 5 & \\
3^{\prime \prime} & 3 & 3^{\prime} \\
3^{\prime} & 1 & 3^{\prime \prime} \\
15^{\prime} & 3^{\prime} &
\end{array}
$$

2 divided by 7

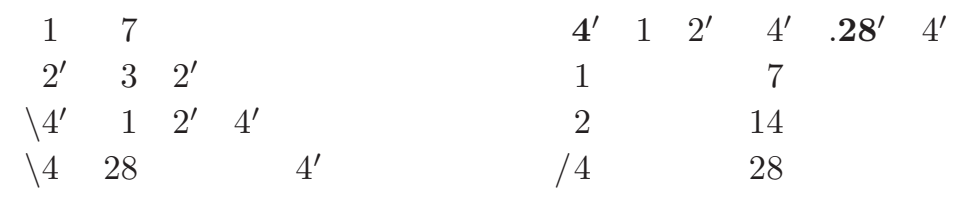

\footnotetext{
${ }^{1}$ The meaning by Chase is "Get 2 by operating on 3, that is, by multiplying 3."
} 


$$
\text { "filep" — 2005/2/17 — 19:05 — page 340 — \#4 }
$$

\section{Plate 6}

2 divided by 19

$$
\mathbf{1 2}^{\prime} \quad 1 \quad 2^{\prime} \quad 12^{\prime} \quad \mathbf{7 6}^{\prime} \quad 4^{\prime} \quad \mathbf{1 1 4}^{\prime} \quad 6^{\prime}
$$

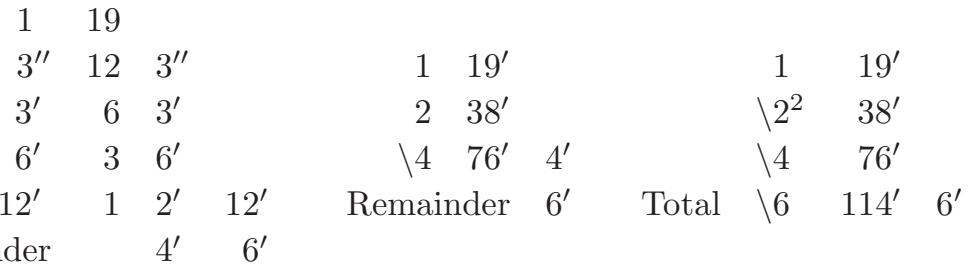

Remainder

\section{$\underline{\text { Plate } 30^{3}}$}

2 divided by 89

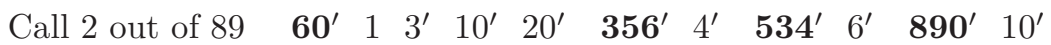

Working out

$\begin{array}{crrrrr} & 1 & 89^{4} & & & \\ \text { Find } & 60^{\prime} & 1 & 3^{\prime} & 10^{\prime} & 20^{\prime} \\ \backslash 4 & 356^{\prime} & & 4^{\prime} & & \\ \backslash 6 & 534^{\prime} & & 6^{\prime} & & \\ 10 & 890^{\prime} & & 10^{\prime} & & \\ 10 & & & \end{array}$

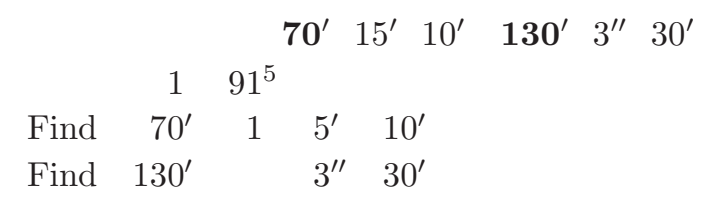

In each case the scribe gives the results in red symbols (bold face characters here), for the other symbols he uses black ink. This suggests that the "working out" calculations are for the verification of the results and not to obtain them as it is generally supposed. Let us quote two other researchers who arrived at the same conclusion:

"The scribe first states what solution he has selected and then, by ordinary multiplication, proves that the equality is correct." [7]

\footnotetext{
${ }^{2}$ The backlashes before 2 and 4 were added by Chase

${ }^{3}$ Some digits were blurred in this table.

${ }^{3}$ Added by Chase (and Clagett).

${ }^{5}$ Added by Chase (and Clagett).
} 


$$
\text { "filep" — 2005/2/17 — 19:05 — page } 341 \text { — \#5 }
$$

"The answer to the problem (27/30 or 9/10) is given first and then verified, not explained. It may be, in truth, that the author had nothing to explain, that the problem was solved by trial and error - as it has been suggested, the Egyptians solved all their mathematical." (see [11], Vol. 1, p. 173)

In our opinion these statements are correct but unfortunately give no orientation in finding the method by which the results have been obtained. Thus, we have to turn again to the Recto itself. From the plates quoted one can conclude that the "calculate with $n$ till you get 2 " procedure consists of more than one step. Remembering also the scholiast's words on logistics, it creates a picture of a one-by-one movement along a 2 unit long line segment from the beginning to the end. The boldface characters of the results show how many parts the two units be divided into to reach 2. RMP's Problem 31 suggests that the division into 21 aliquot parts was a step-by-step process: "A quantity, $3^{\prime \prime}$ of it, $2^{\prime}$ of it, $7^{\prime}$ of it, added to it, become it: 33". Several centuries later, Plato followed the same logic in division: "Let the whole number be first divided into two parts, and then into three; and the whole number is further capable of being divided into four or five parts, or any number of parts up to ten" (Laws 737e). To verify our conjecture compare the alleged Egyptian division method to ours in case of $2: 7$.

\section{Division of 2 by 7 using a method of today and the suppose one of RMP}

Divide 2 by 7 can be reformulated in Egyptian style like this: calculate with 7 till you find 2. We use (modern) decimal fractions, so the two units must be divided into 10 equal parts each, and the question is: how many times can we calculate with 7 to get as close to 2 as possible. In the first step we can calculate twice to reach 14, the "remainder" is 6 tenths: $20=2 \cdot 7+6$

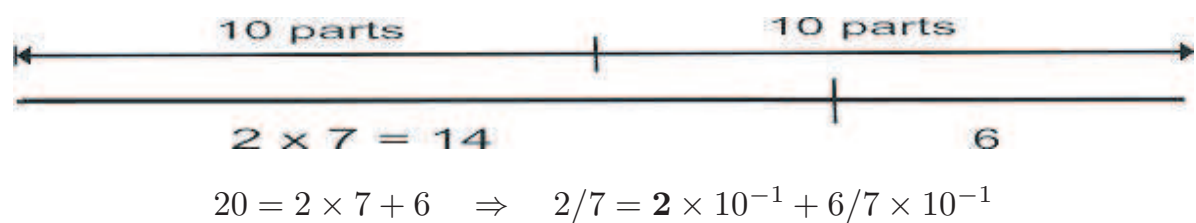

Figure 1
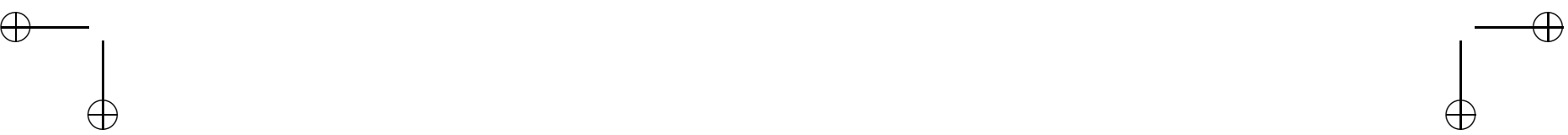
After dividing the remaining 6 tenths again into 10-10 equal parts, we can calculate with 7 eight times to reach 56 (coming 60 as close as possible), leaving behind 4 hundreds to cover:

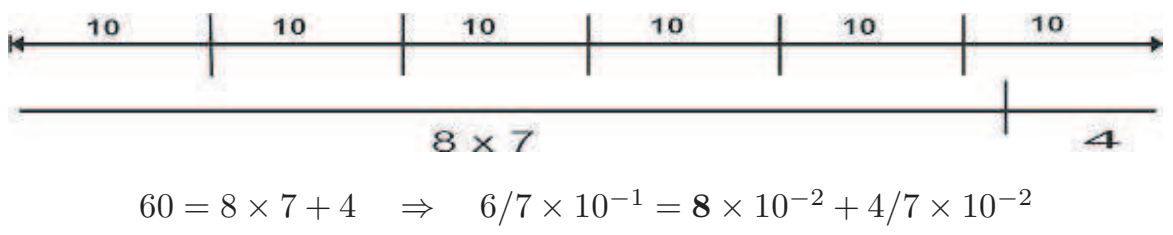

Figure 2

Continuing with this method we get the further digits of the decimal fraction form of $2 / 7$ :

$$
\begin{array}{ll}
40=5 \cdot 7+5 & \mathbf{5} \cdot 10^{-3} \\
50=7 \cdot 7+1 & \mathbf{7} \cdot 10^{-4} \\
10=1 \cdot 7+3 & \mathbf{1} \cdot 10^{-5} \\
30=4 \cdot 7+2 & \mathbf{4} \cdot 10^{-6} \\
20=2 \cdot 7+6 & \mathbf{2} \cdot 10^{-7}
\end{array}
$$

Thus we have the following periodic fraction as the (unique) result: $2 / 7=$ $0.2857142 \ldots$ We can state on the basis of the cited examples from the literal translation of Recto that the Egyptian method probably was very similar to our modern division algorithm method with two exceptions. Having no multiplication concept they could not ask: "how many times can we calculate?" If they had interpreted $2 / 7$ as 2 times $1 / 7$ the different unit fraction decompositions would have become meaningless. Further, not having any consequent numeral system for parts the Egyptians were free to divide the units into any number of equal parts in each step of the division algorithms. We remark that in RMP "quantity" was used for number when it was connected to division. The problem $2: 7$ for an Egyptian scribe probably meant the following: how many parts must the unit be divided into so as to get 2 by calculating with 7 (always only once!)? Bisecting the two units we have 4 parts which are too few to calculate with 7 , so bisect again each part, i.e. divide the (original) units into 4-4 parts. Calculating with 7 we cover 7 parts (one unit, half unit, quarter unit) leaving only one part till 2 . Grafically: 


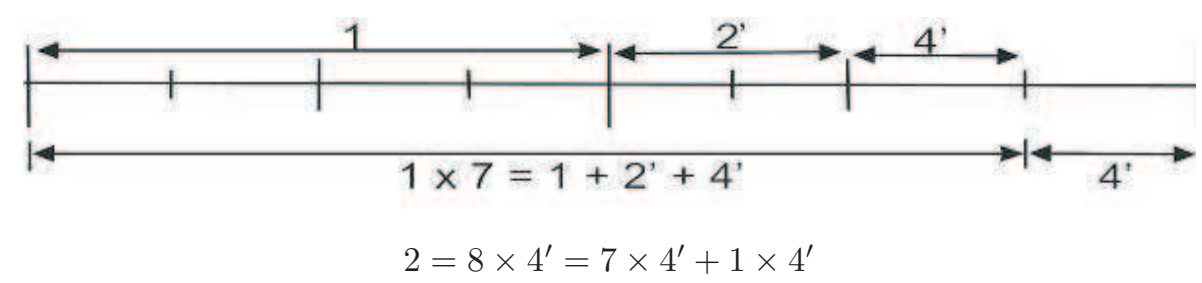

Figure 3

Since we have not yet reached 2, we have to put the question again: how many parts must the remaining new unit(s) be divided into so as to get 2 by calculating with 7 (once!)? The answer is clear: into 7 parts. Each new part is the $28^{\text {th }}$ part of the original unit, so:

$$
2=7 \cdot 4^{\prime}+1 \cdot 4^{\prime}=7 \cdot 4^{\prime}+7 \cdot 28^{\prime} \Rightarrow 2: 7=4^{\prime}+28^{\prime} \quad(=1 / 4+1 / 28) .
$$

This is exactly the result that we find in RMP. This division method is always finite, but can result different unit fraction decomposition due to the "freedom" in the division procedure. E.g. after halving we can continue by trisecting, getting 12 parts altogether (sixth parts of both units). Calculate with 7 let us see the result:

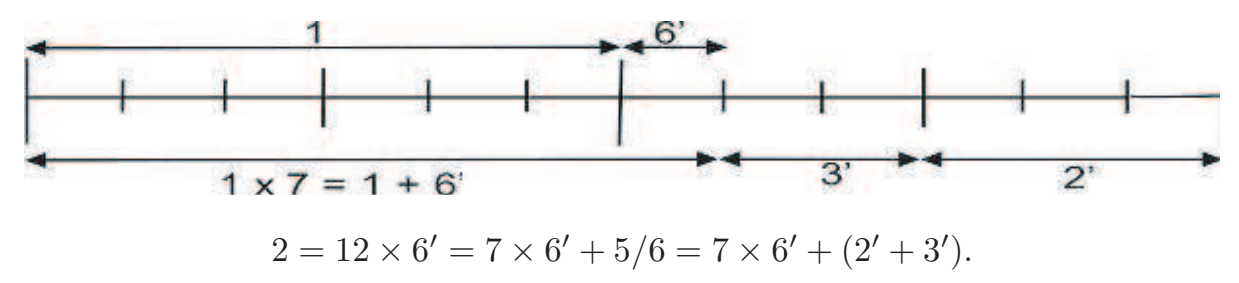

Figure 4

The "remainder" here is 5/6 for us, but for the Egyptian 5/6 had no meaning, but they could decompose it as a sum of $3^{\prime}+2^{\prime}$ by Figure 4 . Each of them must be divided into 7 parts to get to 2 by calculating with 7 . The obtained seventh part of $2^{\prime}$ and $3^{\prime}$ will be the $14^{\text {th }}$ and $21^{\text {st }}$ part of the original unit. Thus we have:

$$
2=7 \cdot 6^{\prime}+7\left[7^{\prime}\left(2^{\prime}+3^{\prime}\right)\right] \Rightarrow 2: 7=6^{\prime}+7^{\prime}\left(2^{\prime}+3^{\prime}\right)=6^{\prime}+14^{\prime}+21^{\prime} .
$$

This solution is not only our speculation, since it has been found in the tomb of an architect for Queen Hatsepsut (1520-1480, B.C.). The finding is recorded as Ostracon No. 153. 


$$
\text { "filep" — 2005/2/17 — 19:05 — page 344 — \#8 }
$$

To get these two decompositions we - and probably the inventor scribe(s) started the division by halving. "Two-thirding" was the other favourite starting step for the scribes, as e.g. in the quoted Problem 31 of RMP. Thus we can divide each unit into $3^{\prime \prime}$ and $3^{\prime}$ parts, then bisect $3^{\prime \prime}$. (This method is characteristic for Egyptian mathematics and connected to the special role of 2/3.) Finally we bisect each third part:

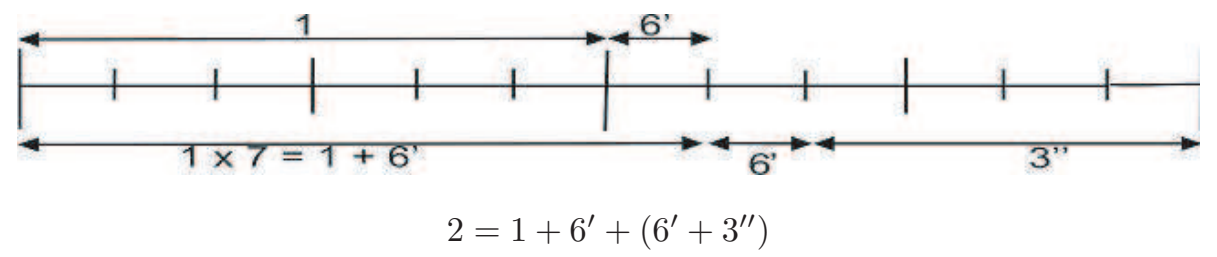

Figure 5

The remainder here $3^{\prime \prime}+6^{\prime}(=5 / 6)$, so each must be divided into $7-7$ parts to reach 2 by calculating again with 7 . Thus:

$$
2=7 \cdot 6^{\prime}+7 \cdot 7^{\prime}\left(3^{\prime \prime}+6^{\prime}\right) \Rightarrow 2: 7=6^{\prime}+7^{\prime}\left(3^{\prime \prime}+6^{\prime}\right) .
$$

From RMP Problem 61/B we know how the Egyptians multiplied an uneven part by $3 "$. Since $3 "=2^{\prime}+6$ (see Appendix 3 ), so

$$
2: 7=6^{\prime}+7^{\prime}\left(2^{\prime}+6^{\prime}\right)+42^{\prime}=6^{\prime}+14^{\prime}+42^{\prime}+42^{\prime}=6^{\prime}+14^{\prime}+21^{\prime},
$$

getting the same result as before. Moreover, the two methods of Figures 4 and 5 establish the important equality $2^{\prime}+3^{\prime}=3^{\prime \prime}+6^{\prime}(=5 / 6)$, which is also in Appendix 3.

One can ask: What was the reason for these different approaches? We mentioned that these problems were of practical origin, and the scribes had to solve them not only in theory, but also in practice. The first six problems of RMP require the distribution of $1,2,6,7,8,9$ loaves among 10 men, so we can interpret $2 / 7$ as distribution of 2 loaves among 7 men. The first solution needs $2+4+6=12$ cuts, the second $2+8+6+6=22$ cuts, while the third $2+2+6+6=16$ cuts. From here we can see that the first solution is the best, and that the two other ones are equal only theoretically but not practically.

To find the decomposition $12^{\prime}+76^{\prime}+114^{\prime}$ of $2 / 19$ on Plate 6 the scribe probably performed the following steps: dividing the units into $12-12$ parts by bisecting-bisecting-trisecting order, then calculating with 19 yields 19/12 = $1+$ $2^{\prime}+12^{\prime}$ leaving $5 / 12=4^{\prime}+6^{\prime}$ to be covered. 


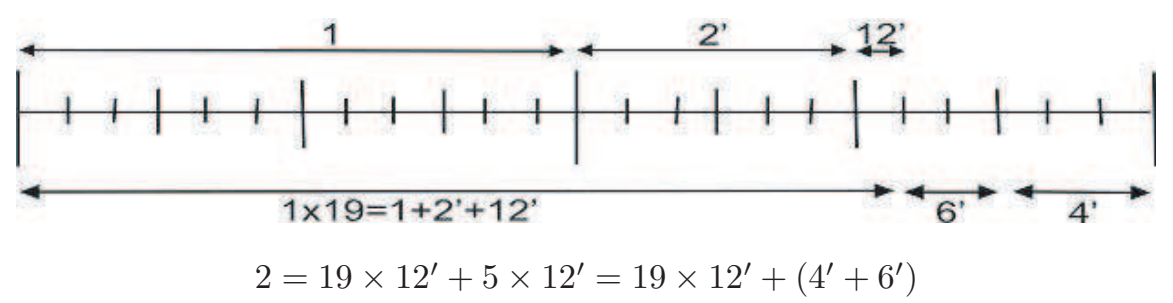

Figure 6

Now $6^{\prime}$ and $4^{\prime}$ must be divided into $19-19$ parts to "find" 2 resulting $76^{\text {th }}$ and $114^{\text {th }}$ parts of the original unit. Thus we have:

$$
2=19 \cdot 12^{\prime}+19^{\prime} \cdot\left(4^{\prime}+6^{\prime}\right) \Rightarrow 2 / 19=12^{\prime}+76^{\prime}+114^{\prime}
$$

One can say it was only by luck that we found the results in this manner. We will show later that all entry of RECTO can be reached similarly. To make it easier we modified its values according to the first "results" lines of Chase's literal translation (see Appendices 1 and 2).

Now we show that the calculations below the first line can only be the verification of the results obtained by the above method. The idea behind the scribe's "proof" is the following simple algebraic identity: $n / n m=1 / m$. In details: if $n$ is taken as unit, then $m$ corresponds to $m n$ consequently $n^{\prime}$ corresponds to $m^{\prime} n^{\prime}$ :

$$
(1 \leftrightarrow n) \Leftrightarrow(m \leftrightarrow m n) \Leftrightarrow\left(m^{\prime} \leftrightarrow m^{\prime} n^{\prime}\right)
$$

For instance, let $n=7, m=4$. If $1 \leftrightarrow 7$, then $4^{\prime} \leftrightarrow 4^{\prime} \cdot 7^{\prime}=28^{\prime}$. Since they could not divide directly by 4 , they made the division by successive halving (see $2: 7$ on Plate 2) with the help of halving tables the existence of which is very probable.

The upper three lines of the left column on Plate 2 verify that if we divide the two units into 4-4 parts and calculate with 7 once we really get $1+2^{\prime}+4^{\prime}$ (from 2). The two right columns prove the second part of the result line $\left(\mathbf{2 8}^{\prime} 4^{\prime}\right)$ by conversing $\left(m^{\prime} \cdot n^{\prime} \leftrightarrow m^{\prime}\right)$ into $(m n \leftrightarrow n)$. The product was calculated by doubling.

In case of $2: 19$ (Plate 6) the method is the same. The three parts of the first line are verified in the subjacent columns. The words "remainder", "total" help to understand the three steps used to find 2 by calculating with 19 (always only once!). In the first column the division 19 by 2 is made in two steps: first calculating the two-third, after halving it. This special role of $2 / 3$ is 


$$
\text { "filep" — 2005/2/17 — 19:05 — page 346 — \#10 }
$$

characteristic for Egyptian arithmetic and closely connected to the emergence of fraction concept. We will discuss this issue later.

One can also say - in spite of the above argument, and examples showed that the calculations are yet for getting the results and not for verifying them. The two decompositions on Plate 30 contradict this view, since no calculations can be found below the first lines, only the reproduction of them. The scribe surely used the logistic method to find the decomposition. Let us try to reconstruct his method with the help of Appendix 1: $2 / 89=60^{\prime}+89^{\prime}\left(4^{\prime}+6^{\prime}+10^{\prime}\right)$. From here we can see that after dividing the two units $60-60$ parts and calculating with 89 we reach $89 / 60=(60+15+10+4) / 60=1+4^{\prime}+6^{\prime}+15^{\prime}$. Then there remains $31 / 89=(15+10+6) / 89=4^{\prime}+6^{\prime}+10^{\prime}$ to be covered by calculating with 89 on each of them. Since $60=2^{2} \cdot 3 \cdot 5$ the division into 60 parts may have been made in three or four steps and even in different order. After some trial we find that bisecting, bisecting, trisecting and "fifthing" gives the desired result. ("Fifthing" and similar words are not regular English word, but for brevity's sake we will use them in this paper.)

\section{Problem No. 4 of RMP}

Now we show that our "logistic" method fits well not only to the Recto, but to many other problems of RMP. Take e.g. the 4th problem of the papyrus:

"The making of loaves 7 for man 10. Make thou: 3" 30' times 10; there result 7 .

The producing of the same:

$\begin{array}{rllll}1 & & 3^{\prime \prime} & 30^{\prime} & \\ \backslash 2 & 1 & 3^{\prime} & 15^{\prime} & \\ 4 & 2 & 3^{\prime \prime} & 10^{\prime} & 30^{\prime} \\ \backslash 8 & 5 & 2^{\prime} & 10^{\prime} & \end{array}$

Total loaves 7 ; it, this is."

The phrase "producing of the same" makes it clear that the calculation followed must have served only to verify the result obtained probably by "logistic" method. Let us use first this method in a formal way. Bisect each loaf and calculate with $10: 1 \cdot 10+4 \cdot 2^{\prime}$. The remainder is 4 half loaves. Trisecting them we have 12 sixth loaves. Calculating with 10 there remain 2 sixth parts. Cutting each into $5-5$ parts and calculating with 10 we reach 2 . Thus the result: $7 / 10=2^{\prime}+6^{\prime}+30^{\prime}$ 


$$
\text { "filep" — 2005/2/17 — 19:05 — page 347 — \#11 }
$$

However, our scribe's result is $7 / 10=3^{\prime \prime}+30^{\prime}$. What might have been the motivation behind this result? Our scribe was not a pure mathematician at all, as we mentioned before. He had to solve this problem in practice, too, not only in head. Our solution requires altogether 23 cuts: bisecting 7 loaves ( 7 cuts), trisecting the four half ones ( 8 cuts), cutting into $5-5$ parts the two sixth ones ( 8 cuts). Instead the scribe cut each loaf into two third and one-third parts (7 cuts). Putting together two one third loaves we get one two-third loaf. Thus we have 10 two-third loaves and one-third loaf. Cutting this third one into 10 parts there result ten $30^{\text {th }}$ parts $\left(9\right.$ cuts). So each man got a two-third and a $30^{\text {th }}$ loaf by only 16 cuts.

The scribe, who invented the decomposition $7 / 10=2^{\prime}+5^{\prime}$, was even more economical. He bisected only five loaves ( 5 cuts), and gave each person a half loaf (calculating with 10 he reached 5 ). Then cut the remaining 2 loaves into $5-5$ equal pieces ( 8 cuts), and gave fifth loaves to each. Thus he solved the problem by 13 cuts only. This solution was found on the so-called Akhim Papyrus, which was compiled between the sixth and ninth centuries A.D.

The two solutions establish the equation $3^{\prime \prime}+30^{\prime}=2^{\prime}+5^{\prime}(=7 / 10)$. Several other relations among unit fractions were known in ancient Egypt derived probably in a similar way (see some of them in Appendix 3).

We have tried to reconstruct the way of thought of the inventor scribes, but the copying scribe, Ahmes might have worked differently. He began the first section containing Problems $1-6$ with the division table $n / 10(0<n<9)$, where $7 / 10=3^{\prime \prime}+30^{\prime}$. Thus he could simply replace $2^{\prime}+5^{\prime}$ by $3^{\prime \prime}+30^{\prime}$. It is interesting that in Problem 54 he left $2^{\prime}+5^{\prime}$ for $7 / 10$ :

"What equal areas should be taken from 10 fields if the sum of these areas is to be 7 setat?

Multiply 10 so as to get 7 .

110

$\backslash 2^{\prime} \quad 5$

$\backslash 5^{\prime} \quad 2$

Total $2^{\prime} 5^{\prime}$."

Using different decompositions for "loaves" and "areas" is surprising for us, but was natural in ancient times. In his paper [4] Friberg analysed some protoSumerian tablets and found similar phenomenon. For example, Sumerians used different units for vertical and horizontal measurement. Depending on what was numbered they used different signs, and even different number systems. They had area numbers and capacity numbers represented by different symbols. For 


$$
\text { "filep" — 2005/2/17 — 19:05 — page 348 — \#12 }
$$

Egyptians and Sumerians number and part were not absolutely abstract concepts, but were connected to the things being numbered or distributed.

Thousands years later, Proclus (410-485 AD) the Byzantine commentator also wrote on numbers in similar sense: "... the student of calculation...gives them names from the things being numbered, called them sheep numbers or cup numbers. He does not assert, as does the arithmetician, that something is least; nevertheless to any given class he assumed a least, for when he is counting a group of man, one man is his unit." [14] (The names: sheep and cup numbers were taken from Plato's Laws 819 BC.)

\section{How the entries of the Recto were calculated?}

When the denominator is a prime number, the reader can reconstruct the scribe's supposed logistic method with the help of examples given and of Appendix 1. If one has the literal translation of Chase the job is easier.

The case of $2 / 3$ seems to be meaningless since $2 / 3$ itself is a unit fraction (part). What the scribe wrote is probably the result obtained by "calling 2 out of 3". As in Problem 4, the scribe divided the two units into two complementary parts $2 / 3-1 / 3$. Thus he got three two-thirds, so calculating with 3 (once) he really reached 2 . The idea behind the "proof" $\left(\mathbf{3}^{\prime \prime} 2\right)$ might be the following: if we take 3 as unit, then 2 is two-third of the unit.

For us this solution is hardly acceptable, but for ancient people was natural, and was closely connected to the emergence of fraction concept. Most historians agree that the concept of natural number comes from counting while that of fraction from measurement. The claim for more and more correct measurement of continuous quantities led to fractions through the division of the measure unit into smaller parts. The first part (fraction) was the half by bisecting the unit. After the two equal complementary parts $(1 / 2-1 / 2)$ the next ones were the $2 / 3$ and the $1 / 3$. The Egyptians called them two parts and third parts, and the Chinese greater part and lesser part (see [15, pp. 19-20] for Egypt and [10, pp. 34-35] for China). These parts had special symbols in both cultures.

The Chinese names help us to understand why the Egyptians calculated the third in two steps (two-thirding, halving). Really, if one has to trisect e.g. a line segment, one first divides it into a larger and a smaller part $(2 / 3$ and $1 / 3)$, then bisect the larger one.

The case of 2/101 is also interesting, and the decomposition given needs another explanation. From the boldface parts of the third column of Appendix 1 


$$
\text { "filep" — 2005/2/17 — 19:05 — page 349 — \#13 }
$$

one can conjecture that the division into 2, 3, 5 and 7 equal parts were the only allowed basic decompositions. Dividing into more parts was made in consecutive steps of these in different order. For example, in Problem 32 (similarly to Problem 31) of RMP instead of a quantity and its twenty-first part being 33, what is the quantity, the scribe wrote: "A quantity its 3 ", and its 4 ' added together, become 2. What is the quantity?"

The fundamental role of $5^{\prime}$ and $7^{\prime}$ (besides $2^{\prime}$ and 3") in early Egyptian mathematics is confirmed by the following quotations from the books of Genesis and Joshua of the Holy Bible (King James Version):

"It will happen at the harvests, that you shall give a fifth to Pharaoh, and four parts will be your own, ..." (Genesis, 42.24)

"They shall divide it into seven portions: ..." (Joshua, 8.5).

Even thousands years later, the Arabs called those fractions the denominator of which contained only 2, 3, 5 or 7 as prime factors "expressible", and the others "inexpressible" (see [16], p. 56]). In later times the Egyptians used the direct division by 10 , too.

Using only these distributions and calculating by 101 the scribe could not find a proper remainder, which is a sum of at most three different simple unit fractions. Thus he chose the simplest solution, the general form of which is the following: calculate with $\mathrm{n}$ to get 1 , then write the remainder unit as the sum of $2^{\prime}+3^{\prime}+6^{\prime}$, finally calculate again with $n$ to get 2 . The scribe could have used this rule in all other cases, too. A computer investigation confirms (see [6], 69) that the only possible decomposition of $2 / 101$ into at most four different unit fractions is the one, which the scribe gave in the table.

\section{Decomposition of fractions $2 / n$ with composite odd denominator}

This case can be led back to the prime one as Appendix 2 shows. The case of $2 / 35$ and $2 / 91$ are exceptional since the decompositions used for $2 / 7$ and $2 / 13$ are different from those of Recto. Chase translated the decomposition of $2 / 35$ in [2] as follows:

$\begin{array}{rrrrrrrrr} & 35 & \mathbf{3 0}^{\prime} & 1 & 6^{\prime} & \mathbf{4 2} & 3^{\prime \prime} & .6 \\ & 6 & & 7 & & & 5 & & \\ \backslash 30^{\prime} & 1 & 6 & & & & & & \\ \backslash 42^{\prime} & 3^{\prime \prime} & 6 & & & & & & \end{array}$


Since $2 / 35=1 / 5 \cdot 2 / 7$, so we guess the scribe might have started with the decomposition of $2 / 7$, but replaced $4^{\prime}+28^{\prime}$ with the third one in Point 3 , Figure 5 : $2 / 7=6^{\prime}+7^{\prime}\left(3^{\prime \prime}+6^{\prime}\right)$. Applying $2 / 35=1 / 5 ? \cdot 2 / 7$ and the equalities $3^{\prime \prime}+6^{\prime}=2^{\prime}+3^{\prime}$, $10^{\prime}+15^{\prime}=5^{\prime}\left(2^{\prime}+3^{\prime}\right)$ from Appendix 3 have:

$$
2 / 35=5^{\prime}\left[6^{\prime}+7^{\prime}\left(3^{\prime \prime}+6^{\prime}\right)\right]=5^{\prime} \cdot 6^{\prime}+7^{\prime} \cdot 5^{\prime}\left(2^{\prime}+3^{\prime}\right)=5^{\prime} \cdot 6^{\prime}+7^{\prime} \cdot 6^{\prime}=30^{\prime}+42^{\prime} .
$$

The explanation line below the result one shows the key role of the numbers $6,7,5$ in finding this solution. Since the scribe wrote an extra explanation line only in this case, means that even the scribe regarded this decomposition as complicated.

We quoted the decomposition of $2 / 91$ in Point 2 (Plate 30 ). The part $70^{\prime}$ in the result line shows that first $2 / 13$ was decomposed, and then it was multiplied by $1 / 7$. The units were divided into $10-10$ parts in two steps: halving, fifthing. Calculating with 13 , we reach $1+10^{\prime}+15^{\prime}$ leaving $2^{\prime}+5^{\prime}$ to cover.

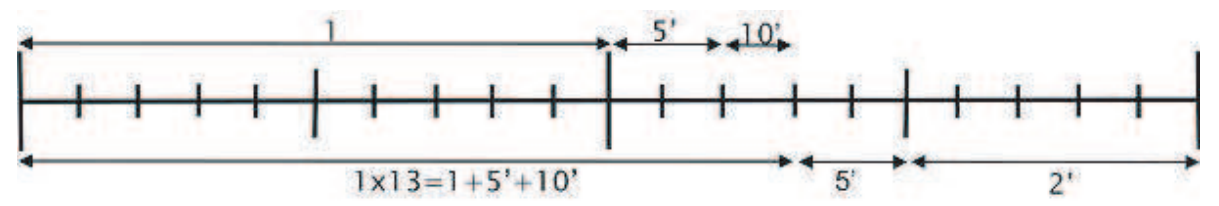

Figure 7

Now using the equality $14^{\prime}+35^{\prime}=7^{\prime} \cdot\left(2^{\prime}+5^{\prime}\right)=10^{\prime}$ from Appendix 3 we get:

$$
\begin{aligned}
2 / 91 & =1 / 7 \cdot 2 / 13=7^{\prime} \cdot\left[10^{\prime}+13^{\prime}\left(2^{\prime}+5^{\prime}\right)\right] \\
& =70^{\prime}+13^{\prime} \cdot 7^{\prime}\left(2^{\prime}+5^{\prime}\right)=70^{\prime}+13^{\prime} \cdot 10^{\prime}=70^{\prime}+130^{\prime} .
\end{aligned}
$$

The scribe wrote $3^{\prime \prime} 30^{\prime}$ after $\mathbf{1 3 0}^{\prime}$ in the result line instead of $2^{\prime} 5^{\prime}$, probably because of the same reason we supposed earlier in connection with Problems 4 and 54. The general form of the equalities $5^{\prime}\left(2^{\prime}+3^{\prime}\right)=2^{\prime} \cdot 3^{\prime}$ and $7^{\prime}\left(2^{\prime}+5^{\prime}\right)=10^{\prime}$ are $(n+m)^{\prime} \cdot\left(n^{\prime}+m^{\prime}\right)=n^{\prime} m^{\prime}$, which is an identity. The Egyptians, of course, could not formulate this rule but could visualize it by their "unit variation" method. If we take $(n+m) n m$ as unit, then $n$ corresponds to $(n+m)^{\prime} m^{\prime}, m$ to $(n+m)^{\prime} n^{\prime}$, and $n+m$ to $n^{\prime} m^{\prime}$. Take $n=2, m=3$, then $n+m=5, n m=6,(n+m) n m=30$, $(n+m) n=10,(n+m) m=15$. Thus $n=3$ correspond to $(n+m)^{\prime} n^{\prime}=10^{\prime}$, $m=2$ correspond to $(n+m)^{\prime} m^{\prime}=15^{\prime}$, and $\mathrm{n}+\mathrm{m}=5$ correspond to $n^{\prime} m^{\prime}=6^{\prime}$, so really $10^{\prime}+15^{\prime}=6^{\prime}$, or shortly:

$$
\left(30 \rightarrow 1,3 \rightarrow 10^{\prime}, 2 \rightarrow 15^{\prime}, 5 \rightarrow 6^{\prime}\right) \Rightarrow 10^{\prime}+15^{\prime}=6^{\prime} .
$$




$$
\text { "filep" — 2005/2/17 — 19:05 — page 351 — \#15 }
$$

Supposing the scribe knew this method, i.e. the rule $(n+m)^{\prime} \cdot\left(n^{\prime}+m^{\prime}\right)=n^{\prime} m^{\prime}$, he could simply decompose $2 / 35$ and $2 / 91$ into unit fractions as follows:

$$
\begin{gathered}
12^{\prime}\left(5^{\prime}+7^{\prime}\right)=5^{\prime} \cdot 7^{\prime} 2^{\prime}\left(30^{\prime}+42^{\prime}\right)=35^{\prime} \Rightarrow 2 / 35=30^{\prime}+42^{\prime}, \\
20^{\prime}\left(7^{\prime}+13^{\prime}\right)=7^{\prime} \cdot 13^{\prime} \Rightarrow 2^{\prime}\left(70^{\prime}+130^{\prime}\right)=91^{\prime} \Rightarrow 2 / 91=70^{\prime}+30^{\prime} .
\end{gathered}
$$

\section{Some "why" questions concerning Recto}

First discuss the "necessity" question: why were the decompositions necessary for ancient Egyptians? In Point 3 we mentioned one reason: lack of multiplication concept. Two other explanations can also be added. One is grammatical, i.e. semantic interpretation of their phrase for fraction. Let us quote Sir Alan Gardiner's words:

"For the Egyptian the number following the word $r$ had ordinal meaning;... $r-5$ means 'part 5', i.e. 'the fifth part' which concludes a row of equal parts together constituting a single set of five... . To the Egyptian mind it would have seemed nonsense and self-contradictory to write $r-74$ or the like for $4 / 7$; in any series of seven, only one part could be the seventh, namely that which occupied the seventh place in the row of seven equal parts laid for inspection." [5, pp. 196-197]

Finally there could be a practical reason, too. The Egyptian scribes, as practical minded men, dealing with e.g. the distribution of loaves among people, could not imagine the cutting of more than one loaf all at once, only one at a time. We think these explanations are more proper than that of Waerden's: "senseless accumulation of unit fractions" [15, p. 22].

One can also ask: what about even denominators? Why were not the fractions $2 / n$, where $n=2 m$, written as the sum of different unit fractions? In our opinion the answer is hidden in the Egyptian measurement. To avoid fractions they distributed the basic measure unit into smaller and smaller parts and regarded them as new units. Conversely, to avoid big number of parts they took some multiples of the basic unit for new unit. Chace describes this phenomenon for hekat (basic capacity unit) as follows:

"Furthermore the Egyptians had not only the system of a simple hekat and its parts and multiples, but also systems of a double hekat and a quadruple hekat with their parts and multiples, each part or multiple of a double hekat being twice the corresponding part or multiple of a simple hekat, and each part or multiple 


$$
\text { "filep" — 2005/2/17 — 19:05 — page 352 — \#16 }
$$

of a quadruple four times the corresponding part or multiple of a simple hekat; ..." [2, p. 32]

Thus, if $n=2 m$, then take $2 m$ the new unit. Consequently two parts become one part, so the number of parts clearly $m$, in other words $2 / 2 m=1 / m$.

\section{Concluding remarks}

For some historians of mathematics our paper may cause disappointment being convinced of the existence of some general formula for Recto. D. M. Burton seems to belong to them:

"Ever since the first translations of the papyrus appeared, mathematicians have tried to explain what the scribe's method may have been in preparing this table. Of the many possible reductions to unit fractions, why is

$$
2 / 19=1 / 12+1 / 76+1 / 114
$$

chosen for $n=19$ instead of, say,

$$
2 / 19=1 / 12+1 / 57+1 / 228 ?
$$

No definite rule has been discovered that will give all the results of the table." [1, p. 42]

For teachers of mathematics the most important conclusion is that the introduction of fraction concept should be made in connection with measurement and not through the division of two numbers. The concept-formation should be a step by step process starting from simple unit fractions as unit parts.

Teaching experiences show that children can find the sum of a half and a quarter before they can formulate either the question or the answer in fractional numbers, probably because they link number concept to counting only.

To teach fractions and division has not ever been an easy job. A teacher knowing the historical route from counting to measuring number can make easier the development of fraction concepts to his or her pupils. To start, solving problems similar to bread division ones is suggested, firstly by manipulation of proper devices, then by only drawing circles, rectangles, lines, etc. It is a good way discovering many basic relations among unit fractions, e.g. $3 / 4=1 / 2+1 / 4$. In this stage fractional notation can be introduced, but be careful with interpreting numerators.

To comprehend $3 / 4$ as the result of division 3 by 4 presupposes the concept of division, which firstly should be interpreted in Egyptian manner: calculate 
by 4 till you find 3. Before this, pupils are supposed to solve division problems involving only integers, such as calculate by 4 till you find 12 . Divisions leading to fractions by the method used for $2: 7$ in Point 3 probably is the easiest way to teach division in different number systems. For more details see [3].

\section{Appendices}

\begin{tabular}{|ccc|}
\hline $2 / 5$ & $3^{\prime}+15^{\prime}$ & $3^{\prime}+\mathbf{3}^{\prime} \cdot 5^{\prime}$ \\
$2 / 7$ & $4^{\prime}+28^{\prime}$ & $4^{\prime}+\mathbf{4}^{\prime} \cdot 7^{\prime}$ \\
$2 / 11$ & $6^{\prime}+66^{\prime}$ & $6^{\prime}+\mathbf{6}^{\prime} \cdot 11^{\prime}$ \\
$2 / 13$ & $8^{\prime}+52^{\prime}+104^{\prime}$ & $8^{\prime}+\left(\mathbf{4}^{\prime}+\mathbf{8}^{\prime}\right) \cdot 13^{\prime}$ \\
$2 / 17$ & $12^{\prime}+51^{\prime}+68^{\prime}$ & $12^{\prime}+\left(\mathbf{3}^{\prime}+\mathbf{4}^{\prime}\right) \cdot 17^{\prime}$ \\
$2 / 19$ & $12^{\prime}+76^{\prime}+114^{\prime}$ & $12^{\prime}+\left(\mathbf{4}^{\prime}+\mathbf{6}^{\prime}\right) \cdot 19^{\prime}$ \\
$2 / 23$ & $12^{\prime}+276^{\prime}$ & $12^{\prime}+\mathbf{1 2}^{\prime} \cdot 23^{\prime}$ \\
$2 / 29$ & $24^{\prime}+58^{\prime}+174^{\prime}+232^{\prime}$ & $24^{\prime}+\left(\mathbf{2}^{\prime}+\mathbf{6}^{\prime}+\mathbf{8}^{\prime}\right) \cdot 29^{\prime}$ \\
$2 / 31$ & $20^{\prime}+124^{\prime}+155^{\prime}$ & $20^{\prime}+\left(\mathbf{4}^{\prime}+\mathbf{5}^{\prime}\right) \cdot 31^{\prime}$ \\
$2 / 37$ & $24^{\prime}+111^{\prime}+296^{\prime}$ & $24^{\prime}+\left(\mathbf{3}^{\prime}+\mathbf{8}^{\prime}\right) \cdot 37^{\prime}$ \\
$2 / 41$ & $24^{\prime}+246^{\prime}+328^{\prime}$ & $24^{\prime}+\left(\mathbf{6}^{\prime}+\mathbf{8}^{\prime}\right) \cdot 41^{\prime}$ \\
$2 / 43$ & $42^{\prime}+86^{\prime}+129^{\prime}+301^{\prime}$ & $42^{\prime}+\left(\mathbf{2}^{\prime}+\mathbf{3}^{\prime}+\mathbf{7}^{\prime}\right) \cdot 43^{\prime}$ \\
$2 / 47$ & $30^{\prime}+141^{\prime}+470^{\prime}$ & $30^{\prime}+\left(\mathbf{3}^{\prime}+\mathbf{1 0}\right) \cdot 47^{\prime}$ \\
$2 / 53$ & $30^{\prime}+318^{\prime}+795^{\prime}$ & $30^{\prime}+\left(\mathbf{6}^{\prime}+\mathbf{1 5}^{\prime}\right) \cdot 53^{\prime}$ \\
$2 / 59$ & $36^{\prime}+236^{\prime}+531^{\prime}$ & $36^{\prime}+\left(\mathbf{4}^{\prime}+\mathbf{9}^{\prime}\right) \cdot 59^{\prime}$ \\
$2 / 61$ & $40^{\prime}+244^{\prime}+488^{\prime}+610^{\prime}$ & $40^{\prime}+\left(\mathbf{4}^{\prime}+\mathbf{8}^{\prime}+\mathbf{1 0}\right) \cdot 61^{\prime}$ \\
$2 / 67$ & $40^{\prime}+335^{\prime}+536^{\prime}$ & $40^{\prime}+\left(\mathbf{5}^{\prime}+\mathbf{8}^{\prime}\right) \cdot 67^{\prime}$ \\
$2 / 71$ & $40^{\prime}+568^{\prime}+710^{\prime}$ & $40^{\prime}+\left(\mathbf{8}^{\prime}+\mathbf{1 0}^{\prime}\right) \cdot 71^{\prime}$ \\
$2 / 73$ & $60^{\prime}+219^{\prime}+292^{\prime}+365^{\prime}$ & $60^{\prime}+\left(\mathbf{3}^{\prime}+\mathbf{4}^{\prime}+\mathbf{5}^{\prime}\right) \cdot 73^{\prime}$ \\
$2 / 79$ & $60^{\prime}+237^{\prime}+316^{\prime}+790^{\prime}$ & $60^{\prime}+\left(\mathbf{3}^{\prime}+\mathbf{4}^{\prime}+\mathbf{1 0}\right) \cdot 79^{\prime}$ \\
$2 / 83$ & $60^{\prime}+332^{\prime}+415^{\prime}+498^{\prime}$ & $60^{\prime}+\left(\mathbf{4}^{\prime}+\mathbf{5}^{\prime}+\mathbf{6}^{\prime}\right) \cdot 83^{\prime}$ \\
$2 / 89$ & $60^{\prime}+356^{\prime}+534^{\prime}+890^{\prime}$ & $60^{\prime}+\left(\mathbf{4}^{\prime}+\mathbf{6}^{\prime}+\mathbf{1 0}\right) \cdot 89^{\prime}$ \\
$2 / 97$ & $56^{\prime}+679^{\prime}+776^{\prime}$ & $56^{\prime}+\left(\mathbf{7}^{\prime}+\mathbf{8}^{\prime}\right) \cdot 97^{\prime}$ \\
$2 / 101$ & $101^{\prime}+202^{\prime}+303^{\prime}+606^{\prime}$ & $101^{\prime}+\left(\mathbf{2}^{\prime}+\mathbf{3}^{\prime}+\mathbf{6}^{\prime}\right) \cdot 101^{\prime}$ \\
\hline
\end{tabular}

$\oplus$ 
Appendix 1: Decomposition of fractions with prime denominators in RMP's $2 / n$ table

The first column contains the fractions to be decomposed. In the second column one find the decompositions as they as they appear on the papyrus. In our factorizations (third column) the boldface numbers can be in the first result rows of the relevant $2 / n$ problem in the papyrus showing those unit fractions (remaining parts after the first step), which must be covered by calculating with $n$ (once) to reach 2 in the second step.

\begin{tabular}{|ll|}
\hline $2 / 3 k=2 k^{\prime}+6 k^{\prime}$ & $1 / k \cdot 2 / 3=k^{\prime} \cdot\left(2^{\prime}+6^{\prime}\right)$ \\
\hline $2 / 25=15^{\prime}+75^{\prime}$ & $1 / 5 \cdot 1 / 5=5^{\prime} \cdot\left(3^{\prime}+15^{\prime}\right)$ \\
\hline $2 / 35=30^{\prime}+42^{\prime}$ & $1 / 5 \cdot 2 / 7=5^{\prime}\left[6^{\prime}+7^{\prime}\left(2^{\prime}+3^{\prime}\right)\right]$ \\
\hline $2 / 49=28^{\prime}+196^{\prime}$ & $1 / 7 \cdot 2 / 7=7^{\prime} \cdot\left(4^{\prime}+28^{\prime}\right)$ \\
\hline $2 / 55=30^{\prime}+330^{\prime}$ & $1 / 5 \cdot 2 / 11=5^{\prime}\left(6^{\prime}+66^{\prime}\right)$ \\
\hline $2 / 65=39^{\prime}+195^{\prime}$ & $1 / 13 \cdot 2 / 5=13^{\prime}\left(3^{\prime}+15^{\prime}\right)$ \\
\hline $2 / 77=44^{\prime}+308^{\prime}$ & $1 / 11 \cdot 2 / 7=11^{\prime}\left(4^{\prime}+28^{\prime}\right)$ \\
\hline $2 / 85=51^{\prime}+255^{\prime}$ & $1 / 17 \cdot 2 / 5=17^{\prime}\left(3^{\prime}+15^{\prime}\right)$ \\
\hline $2 / 91=70^{\prime}+130^{\prime}$ & $1 / 7 \cdot 2 / 13=7^{\prime} \cdot\left[10^{\prime}+13^{\prime} \cdot\left(2^{\prime}+5^{\prime}\right)\right]$ \\
\hline $2 / 95=60^{\prime}+380^{\prime}+570^{\prime}$ & $1 / 5 \cdot 2 / 19=5^{\prime} \cdot\left(12^{\prime}+76^{\prime}+114^{\prime}\right)$ \\
\hline
\end{tabular}

Appendix 2: Decomposition of fractions with composite denominators Except 2/35 and 2/91 one can easily derive the results using the entries of Appendix 1 .

\begin{tabular}{|ccc|}
\hline $2^{\prime}+2^{\prime}=1$ & $2^{\prime}+6^{\prime}=3^{\prime \prime}$ & $3^{\prime}+3^{\prime}=3^{\prime \prime}$ \\
\hline $3^{\prime}+6^{\prime}=2^{\prime}$ & $12^{\prime}+4^{\prime}=3^{\prime}$ & $20^{\prime}+5^{\prime}=4^{\prime}$ \\
$30^{\prime}+6^{\prime}=5^{\prime}$ & $42^{\prime}+7^{\prime}=6^{\prime}$ & $15^{\prime}+10^{\prime}=6^{\prime}$ \\
$56^{\prime}+8^{\prime}=7^{\prime}$ & $14^{\prime}+35^{\prime}=10^{\prime}$ & $(2 n)^{\prime}+(2 n)^{\prime}=n^{\prime}$ \\
\hline $2^{\prime}+3^{\prime}+6^{\prime}=1$ & & $7^{\prime}+14^{\prime}+28^{\prime}=4^{\prime}$ \\
& $14^{\prime}+21^{\prime}+42^{\prime}=7^{\prime}$ & \\
\hline $\mathbf{2}^{\prime}+\mathbf{3}^{\prime}=\mathbf{3}^{\prime \prime}+\mathbf{6}^{\prime}(=\mathbf{5} / \mathbf{6})$ & & $\mathbf{2}^{\prime}+\mathbf{5}^{\prime}=\mathbf{3}^{\prime \prime}+\mathbf{3} \mathbf{0}^{\prime}(=\mathbf{7} / \mathbf{1 0})$ \\
\hline
\end{tabular}

Appendix 3: Some basic relations among unit fractions known by Egyptian scribes

We listed here only those ones that somehow related to the content of our paper. Many more can be found in [7]. 


$$
\text { "filep" — 2005/2/17 — 19:05 — page 355 — \#19 }
$$

\section{References}

[1] D. M. Burton, The history of mathematics, Allyn and Bacon, Boston, 1984.

[2] A. B. Chace and H. P. Manning, The Rhind Mathematical Papyrus, Vol 2, MAA, Oberlin (Ohio), 1927.

[3] L. Filep, The development, and the developing of, the concept of a fraction, IJMTL, May 17, 2001, http://www.ex.ac.uk/cimt/ijmtl/ijmenu.html.

[4] J. Friberg, Numbers and Measures in the earliest Written Records, Scientific American (1973), 101-109.

[5] A. Gardiner, Egyptian Grammar, OUP, Oxford, 1957, (third edition).

[6] J. Gillings, Mathematics in the time of the pharaohs, The MIT Press, Cambridge (USA)/London, 1972.

[7] R. J. Gillings, The mathematics of ancient Egypt, in: Dictionary of Scientific Biographies, Vol. 15, Charles Scribner's Sons,, New York, 1978, 681-705.

[8] T. Heath, A history of Greek mathematics, Vol. 1,2, Dover Publications, Inc., New York, 1981.

[9] W. Knorr, Techniques of fractions in ancient Egypt and Greece, Historia Mathematica 9 (1982), 133-171.

[10] J. Nedham and W. Ling, Science and civilisation in China, Vol. 3, CUP, Cambridge, 1970.

[11] J. R. Newman, The Rhind Papyrus, in: The World of Mathematics, Vol. 1, George Allen and Unwin, London, 1961.

[12] T. E. Peet, The Rhind Mathematical Papyrus, London, 1923.

[13] Plato, Laws, tr. B. Jowett, Great Books of the Western World, Vol. 7, Encyclopaedia Britannica, Chicago, 1982.

[14] Proclus, A commentary on the first book of Euclid's Elements, (tr. G. R. Morrow, ed.), Princeton U. P., New Jersey, 1970.

[15] van der B. L. Waerden, Science awakening, tr. A., Wiley, Dresden, New York, 1963.

[16] A. P. Youschkevitch, History of mathematics in the Middle Ages, Gondolat, Budapest, 1982, Russian origin: Moscow, 1961. German edition: Leipzig, 1964 (in Hungarian).

LÁSZLÓ FILEP, PH.D

INSTITUTE OF MATHEMATICS AND COMPUTER SCIENCE

COLLEGE OF NYÍREGYHÁZA, NYÍREGYHÁZA,

P.O.B. 166, H-4401

HUNGARY

E-mail: filepl@nyf.hu

(Received June, 2004) 